\title{
The beneficiation of tailing of coal preparation plant by heavy- medium cyclone
}

\author{
Ataallah Bahrami ${ }^{1} \cdot$ Yousef Ghorbani $^{2} \cdot$ Mirsaleh Mirmohammadi $^{3}$. \\ Behnam Sheykhi $^{1} \cdot$ Fatemeh Kazemi $^{1}$
}

Received: 21 May 2018/Revised: 26 July 2018/Accepted: 1 September 2018/Published online: 17 September 2018

(C) The Author(s) 2018

\begin{abstract}
Dense-medium cyclones have been used for beneficiation of fine particles of coal. In this study, the usability of cyclones in the beneficiation of tailings of a coal preparation plant was investigated. For this purpose, separation tests were conducted using spiral concentrator and heavy medium cyclones with the specific weight of medium $1.3-1.8\left(\mathrm{~g} / \mathrm{cm}^{3}\right)$ on different grading fractions of tailing in an industrial scale (the weight of tail sample was five tons). Spiral concentrator was utilized to beneficiate particles smaller than $1 \mathrm{~mm}$. In order to evaluate the efficiency of cyclones, sink and float experiments using a specific weight of $1.3,1.5,1.7$ and $1.9 \mathrm{~g} / \mathrm{cm}^{3}$, were conducted on a pilot scale. Based on the obtained results, the recovery of floated materials in cyclones with the specific weight of $1.40,1.47$ and $1.55 \mathrm{~g} / \mathrm{cm}^{3}$ are $17.75 \%, 33.80 \%$, and $50 \%$, respectively. Also, the cut point $\left(\rho_{50}\right)$, which is the relative density at which particles report equally to the both products are $1.40,1.67$ and $1.86 \mathrm{~g} / \mathrm{cm}^{3}$. The probable errors of separation for defined specific weights for cyclones are $0.080,0.085$ and 0.030 , respectively. Also, the coefficients of variation was calculated to be $0.20,0.12$ and 0.03 . Finally, it could be said that the performance of a cyclone with a heavy medium of $1.40 \mathrm{~g} / \mathrm{cm}^{3}$ specific weight is desirable compared with other specific weights.
\end{abstract}

Keywords Heavy media cyclones · Coal $\cdot$ Tailings $\cdot$ Coal preparation plant $\cdot$ Tromp curve

\section{Introduction}

Coal is specified as one of the most important energy resources in the world. Approximately $28 \%$ of the energy of the world is provided by coal (BP Statistical Review of World Energy; 2017). Considerable amounts of coal particles are accumulated in the tailing dams of washing plants which can lead to serious environmental problems.

Ataallah Bahrami

a.bahrami@urmia.ac.ir

1 Department of Mining Engineering, Urmia University, Urmia, Iran

2 Department of Civil, Environmental \& Natural Resources Engineering, Luleå University of Technology, Lulea, Sweden

3 School of Mining Engineering, University of Tehran, Tehran, Iran
Recovery of these particles from tailings has several economic and environmental advantages. Maintaining natural resources and reducing the amount of material discharged to the dams are the most important ones (Ashghari et al. 2018). Various investigations have been explored environmental impacts of coal tailing piles on air, soil and groundwater (Meck et al. 2006; Battioui 2013; Kotsiopoulos and Harrison 2017). It is reported in some cases acid mine drainage (AMD) of coal tailing dams contained an amount of sulfates, nitrates, chlorides and heavy metals higher than the average value defined by the World Organization of Health (WHO) (Battioui 2013). These AMDs can cause harmful effects on groundwater quality, river flows and ecology their deposits proximity (Sengupta 1993; Simate and Ndlovu 2014; Kefeni et al. 2017; Peiravi et al. 2017). Moreover, cone shaped damps of coal tailing can potentially be a source of self-ignition and possible explosion (Siboni et al. 2004; Adiansyah et al. 2017). Offering a solution to recover them, can reduce the volume 
of tailing and increase the number of productions and efficiency. In fact, producing coal from tailing is cost-effective, economical and environment friendly. Reprocessing tailings of coal preparation plants is a new approach to coal washing industry.

Gravity separation and flotation are the most common techniques in coal processing and recovery of coal from tailings in large scale (Wills 2011; John et al. 2002). Heavy media separation method is one of the gravity separation methods, which was patented in 1858 by Henry Bessemer (Napier et al. 2006). This method is so advantageous due to the high capacity and efficiency of separation. One of heavy media separators is hydrocyclone which was developed in the 1950s and in the chemical industries due to the simple design, suitable performance and high capacity (Delgadillo and Rajamani 2005). The heavy media cyclone is used extensively in coal processing and in the primary treatment of metal ores such as $\mathrm{Pb}$ and $\mathrm{Zn}$. The modern cyclone for coal preparation is the most effective option for size fraction of $0.5-50 \mathrm{~mm}$ (Chu et al. 2012). In this separator, the centrifugal force causes the heavy particles such as dust or ashes to move to the wall of the cyclone where the particles get down because of the axial velocity and discharge through the underflow of the cyclone (Chu et al. 2009). The heavy media cyclones are installed inclined or upside down (Rayner and NapierMunn 2002).

In order to determine the specific weight of the heavy media liquid of the cyclones, the results of heavy liquid tests are used in different specific weights. Also, evaluation of the separation method or the operation of a gravity separator is usually based on the decomposition of the sink - float, and the washing ability curves (Gupta and Yan 2006). In an ideal separation process, all the particles with a specific weight less than separation density are recovered to concentrate or the light product (coal), and all the particles with a specific weight more than separation density are introduced to tailings or the heavy product (Majumder and Barnwall 2011). It can be stated that there is no ideal separation in any of the separators, and some of the materials are mistakenly divided.

Parameters that influence the mistake of particle splitting are the geometry of separators, machine mechanisms and settings, the composition and feed rate, and product crop, media rheological properties, and relative separation density. In addition, the time required to separate a particle and the settling rate of the particles are effective in the recovery. The performance of a gravity separator in coal treating is commonly determined by plotting a Tromp (distribution) curve which is basically a plot of partition coefficients in term of average specific gravity (Mohanta and Mishra 2009). The separation efficiency can be obtained from the slope of the distribution curve (or the curvilinear curvature). This curve depends on the size of the particles and the type of separator and it is also independent of the operation of sinking and floating (Burt 1984). In Fig. 1, the distribution curve is shown in two ideal and realistic modes. According to the shape, when the curve slope is increasing in the $50 \%$ distribution coefficient, the curve is changed from the realistic mode to the ideal one (vertical slope). This shows that increase in the efficiency of a separator. The greater the slope of the distribution curve is plotted, the better performance of the device is observed (Farzanegan et al. 2013).

In this study, reprocessing of tailings from the Anjir Tange processing plant using a heavy media cyclone was investigated. Gravity separation tests by the heavy media cyclone and sink-float were performed in both industrial and laboratory scale for different size fractions. Finally, the efficiency of heavy media cyclone devices has been evaluated using by Tromp curves. The Tromp curve is an indicative of actual performance of the separation unit since it is independent of feed quality. In case of coal washing, the degree of misplacement is directly depended to the amount particles with a specific weight close to gravity of separation (near-gravity material). However, the coal containing high near-gravity material can be effectively processed by choosing the right process and correct operating parameters.

\section{Materials and methods}

\subsection{Ore sample}

Coal tailings samples were collected from the coal preparation plant of Anjir Tange which actively produces washed coke in central Alborz-Iran. Three methods of

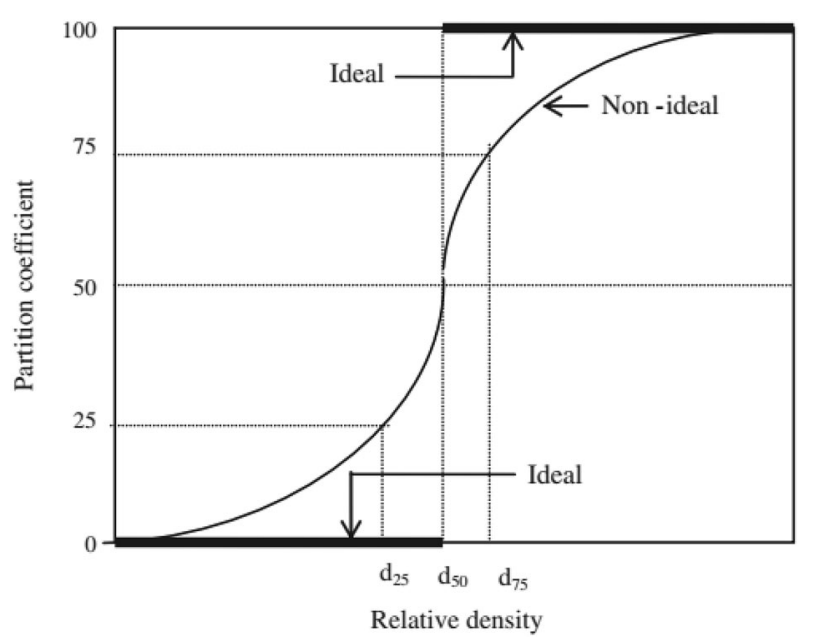

Fig. 1 Ideal and non-ideal distribution curve 
hand sorting, gravity, and flotation are applied in thia plant to supply coke. The tailings aforementioned processes are accumulated in two depots of flotation tailings and the other processing methods. The mass of the piled tailings is 2 million tons with the average ashes between $40 \%$ and $45 \%$. According to studies, $70 \%$ of tailings are produced from jig process with the $44 \%$ valuable coal and $56 \%$ ashes.

\subsection{Experimental approach}

In order to investigate the possibility of reprocessing of tailings from Anjir Tange coal preparation plant by using heavy media cyclones, approximately five tons of tailings sample from tailing dumps were tested with heavy liquids. The spiral tests were also performed in an industrial scale. After the classification of the sample in various grain fractions, heavy media tests were conducted in specific weights of 1.4, 1.5, 1.6, 1.7 and $1.8 \mathrm{~g} / \mathrm{cm}^{3}$.

Based on the results of these experiments, the specific weight of the media were selected, and the heavy medium cyclone tests were carried out on an industrial scale with specific weights of media $1.40,1.47$ and $1.55 \mathrm{~g} / \mathrm{cm}^{3}$. Then, to investigate the efficiency of heavy media cyclones, on both products of tailings, sink-float experiments were carried out in specific weights of $1.3,1.5,1.7,1.9 \mathrm{~g} / \mathrm{cm}^{3}$. Finally, the efficiency of cyclones has been investigated by plotting the corresponding distribution curves.

\section{Results and discussion}

The particle size distribution (PSD) and the amount of ash in each size fractions of the sample are presented in the Figs. 2 and 3. Giving the results of the sieve analysis and the amount of the ash of the coarse-grained tailing, about $50 \%$ of the total samples were in the range of $1-12 \mathrm{~mm}$. The maximum amount of ash is belongs to the fraction of $12-25 \mathrm{~mm}$ with the ash content of $69.70 \%$, which is $21.90 \%$ of the total weight of sample. In Fig. 3b, the results of the sieve analysis and ash content of the flotation tailings are shown. According to this analysis, about $80 \%$ of particles are larger than 40 micrometers with a cumulative ash value of $23.80 \%$.

\subsection{Heavy liquid tests at industrial scale}

In order to investigate the reprocessing capability of the tailings by gravity separation method, heavy liquid tests were carried out in the specific gravity of 1.4, 1.5, 1.6, 1.7 and $1.8 \mathrm{~g} / \mathrm{cm}^{3}$. The results of the heavy media tests in each size fraction are presented and discussed in the following bullet points:
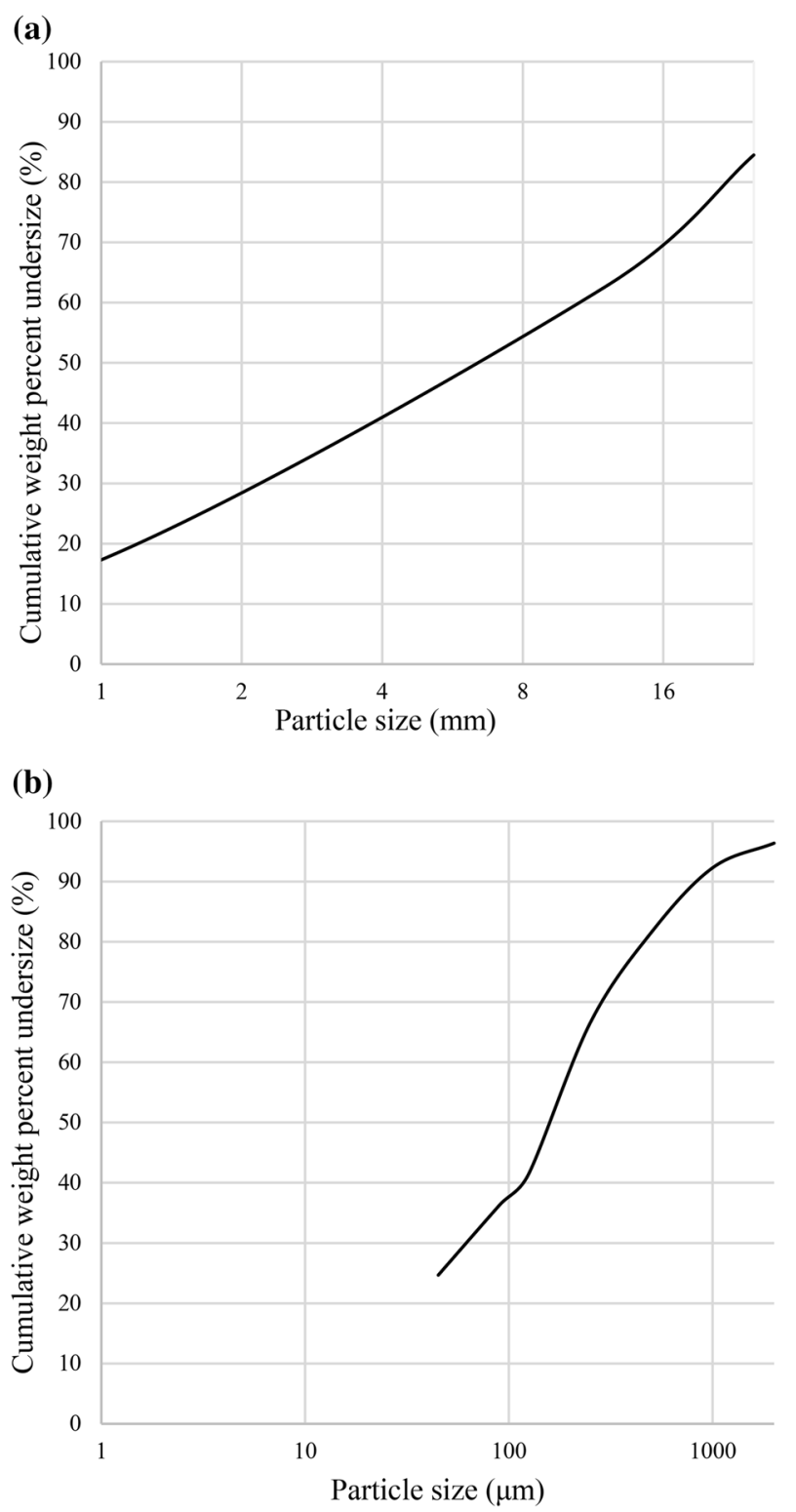

Fig. 2 Sieve analysis of the tailings obtained from the Anjir Tange coal preparation plant. a Tailings of jig, $\mathbf{b}$ tailings of flotation

(1) Particle size greater than $25 \mathrm{~mm}$ Fig. 4a shows the heavy media test result for this size fraction. Based on the results, using a solution with a specific weight of $1.5 \mathrm{~g} / \mathrm{cm}^{3}$, a concentrate with $10 \%$ recovery and $16.40 \%$ ash content and a final tailing with $70.20 \%$ recovery and $73 \%$ ash content was obtained.

(2) Size fractions of $12-25 \mathrm{~mm}$ according to the results of the analysis, the ash content of the feed is $69.70 \%$ and $21.90 \%$. Based on the results of sink and float experiments (Fig. 4b), in a solution with a specific weight of $1.5 \mathrm{~g} / \mathrm{cm}^{3}$, a concentrate with $16 \%$ ash and $8.80 \%$ recovery was achieved. In specific weight of 
(a)

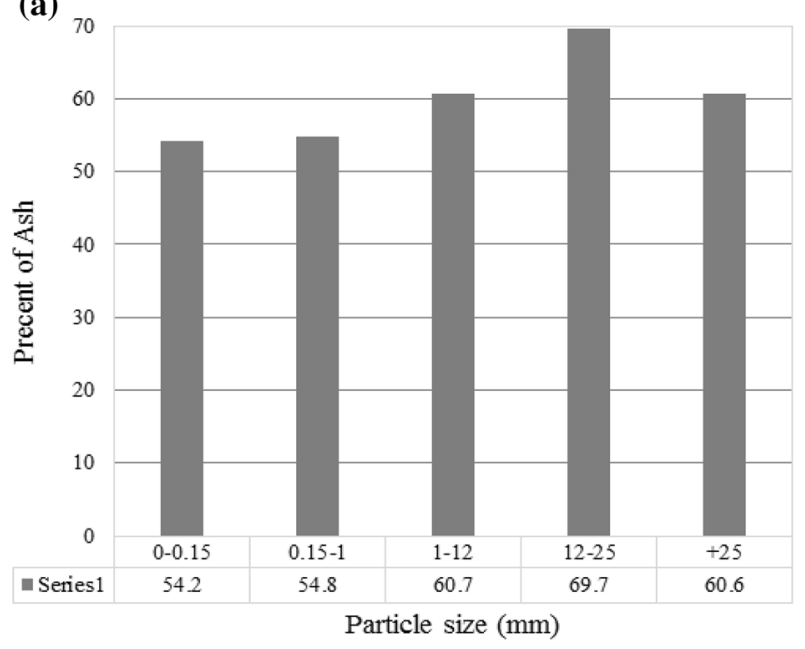

(b)

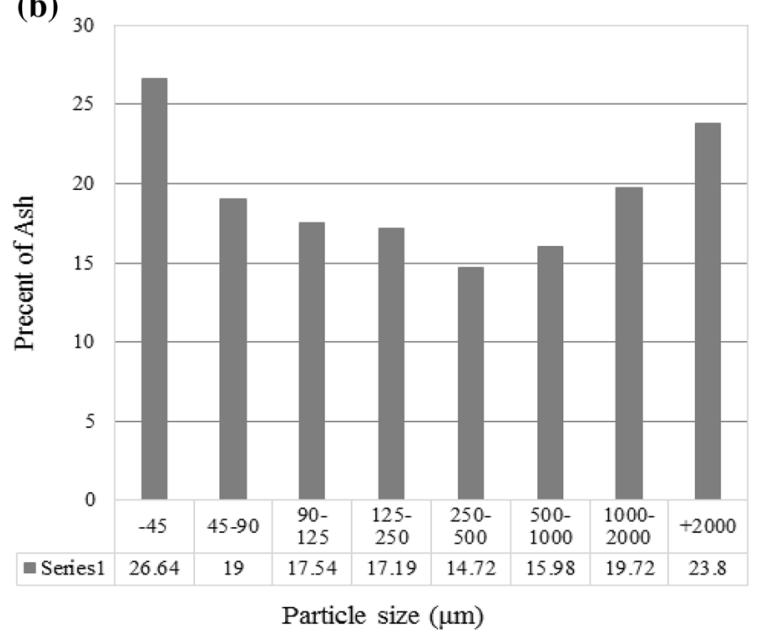

Fig. 3 Ash analysis of the tailings obtained from the Anjir Tange coal preparation plan. a Tailings of jig, $\mathbf{b}$ tailings of flotation

$1.6 \mathrm{~g} / \mathrm{cm}^{3}$, a product with $14.40 \%$ weight percentage of feed and $21.40 \%$ ash with $75.60 \%$ recovery to the tail and $60.60 \%$ ash was obtained.

(3) Particle size fraction of $1-12 \mathrm{~mm}$ This fraction makes up $48.90 \%$ of the feed weight with $60.60 \%$ ash. Based on Fig. 4c, in the specific weight of media $1.6 \mathrm{~g} / \mathrm{cm}^{3}$, the weight percent of the concentrate is $24.30 \%$ and the ash content is $15.10 \%$. In a solution with a specific weight of $1.7 \mathrm{~g} / \mathrm{cm}^{3}$, a product with $28.50 \%$ recovery, and $19.20 \%$ ash was obtained; in this case, the final tailings was $69.90 \%$ of the feed weight with $78.20 \%$ ash.

(4) Particle size greater than $1 \mathrm{~mm}$ the particles which are larger than $1 \mathrm{~mm}$ contain $87 \%$ of the total feed weight. The results of the heavy liquid test on this

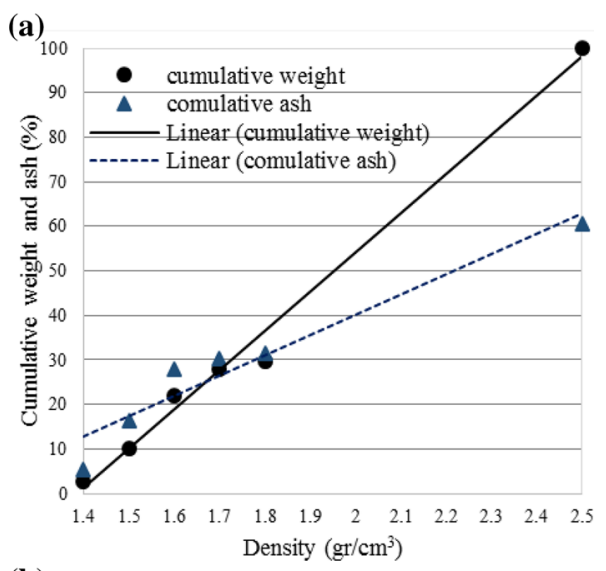

(b)
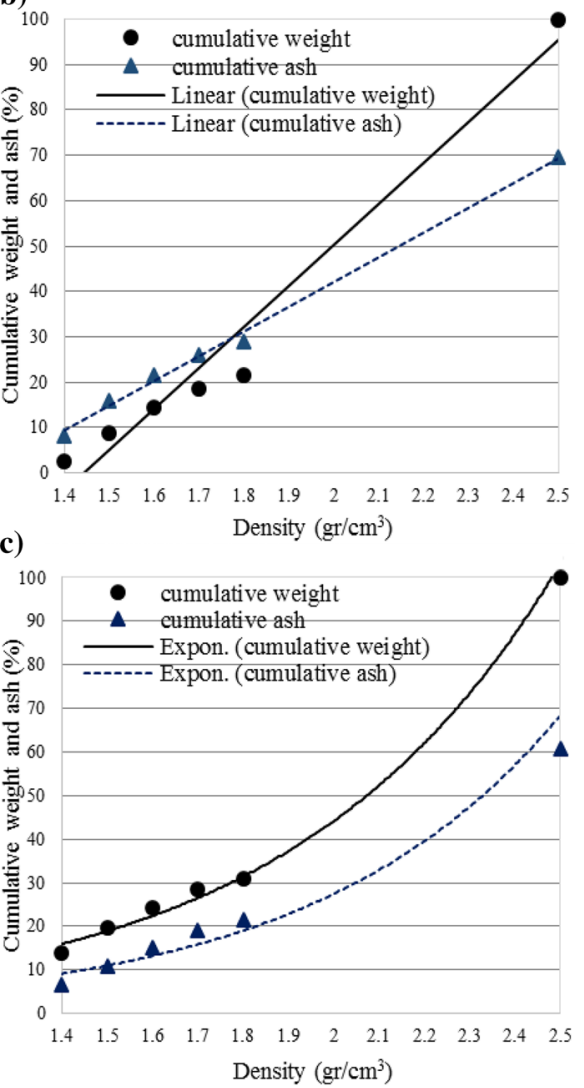

(d)

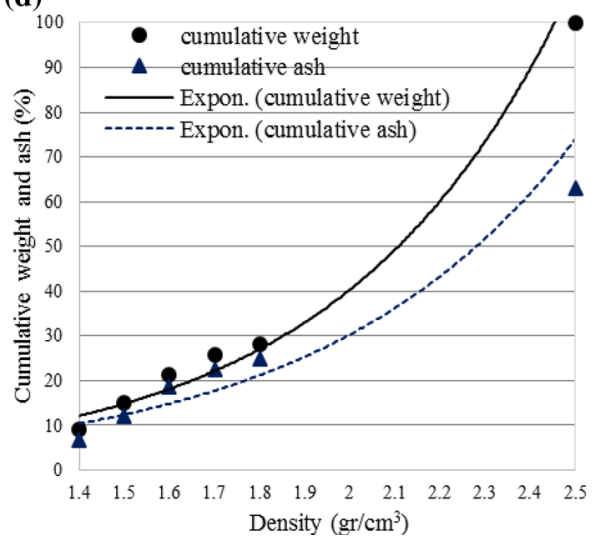


4Fig. 4 The results of heavy liquid and ash contents tests on an industrial scale. a Particle fraction larger than $25 \mathrm{~mm}$, b size fraction 12-25 mm, c size fraction 1-12 mm, $\mathbf{d}$ size fraction larger than $1 \mathrm{~mm}$

size fraction are shown in Fig. 4d. According to the figure, in a specific weight of $1.5 \mathrm{~g} / \mathrm{cm}^{3}$, the weight percent of the concentrate is $15.20 \%$ with $12.20 \%$ ash. Concentrates with $21.40 \%$ and $29.50 \%$ recovery and $18.50 \%$ and $22.60 \%$ ash content, respectively were achieved in special weights of 1.6 and $1.7 \mathrm{~g} /$ $\mathrm{cm}^{3}$. The final tail in the specific weight of $1.7 \mathrm{~g} / \mathrm{cm}^{3}$ is $71.70 \%$ recovery to the tail and $78 \%$ ash.

(5) The fraction with the particle size less than $1 \mathrm{~mm}$ This fraction consists $12.80 \%$ of the feed weight with $54.80 \%$ ash. $12.40 \%$ of this fraction is between 1.00 and $0.15 \mathrm{~mm}$, and $0.40 \%$ is less than $150 \mu \mathrm{m}$. In this part, the primary operation was successful and the particles with a size less than $150 \mu \mathrm{m}$ were removed by using the industrial spiral. The results of this experiment are presented in Fig. 5. According to the results, a product with $32 \%$ recovery and $15.30 \%$ ash was obtained, which is considered as a desirable result.

After preparing thin blade from sample size fraction larger than $12 \mathrm{~mm}$, microscopic studies was conducted and degrees of liberation was obtained. It was observed that coal has a good purity in this fraction, but on the other hand, it has a high degree of contamination with the tail. Despite the unusually crumbling of the coal, to increase the recovery and reduce the amount of ash, this section was dimensioned from the grinding sample, and then a heavy liquid test was performed on fraction of particles which is larger than $1 \mathrm{~mm}$. The results of crushing and heavy liquid tests are presented in Figs. 6 and 7. According to the results, grinding has not had a desirable effect on reducing the amount of ash in this fraction.

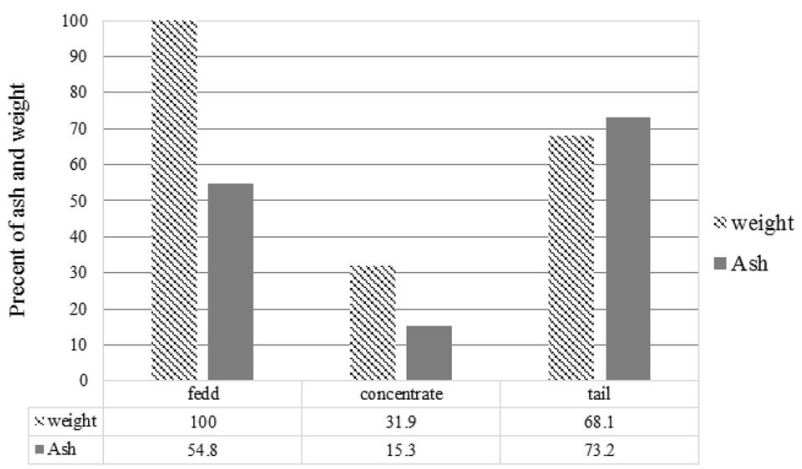

Fig. 5 Industrial spiral test results on size fractions smaller than $1 \mathrm{~mm}$

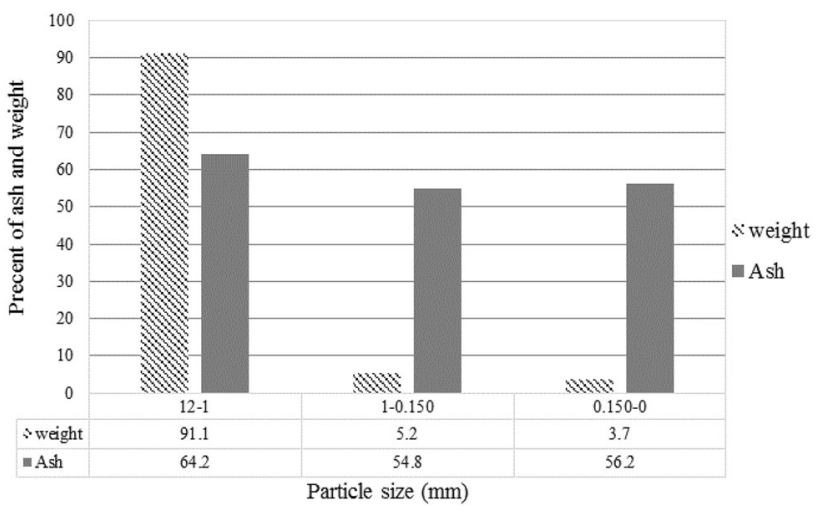

Fig. 6 The results of the sieve analysis and the ash content in the size fraction of larger than $12 \mathrm{~mm}$

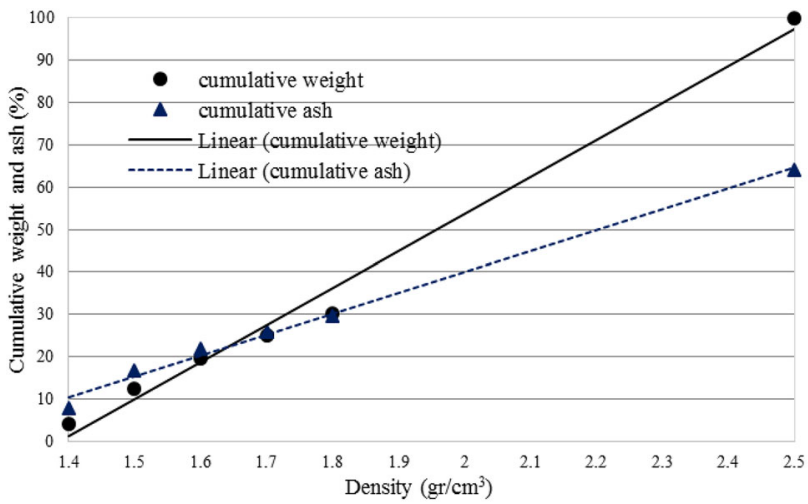

Fig. 7 Test results of heavy liquid and the ash contents of the particles larger than $12 \mathrm{~mm}$

According to the results, by carrying out heavy media test on the tailings of Anjir Tange coal preparation plant, the products of different qualities are produced. The particles which are in the size fraction larger than $1 \mathrm{~mm}$ generated three products with $7 \%$ ash and $19 \%$ recovery, $12 \%$ ash and $30 \%$ recovery, and $45 \%$ ash with the recovery of $22.50 \%$. In the case of combining the spiral product and the fraction larger than $1 \mathrm{~mm}$, concentrate with $18 \%$ ash and $48.50 \%$ recovery is obtained which constitutes about $22.50 \%$ of the feed weight.

To conduct a large-scale heavy media test on an industrial scale, the feedstock was analyzed by using a $20 \mathrm{~mm}$ sieve mesh size. Based on the results, $50 \%$ of the feed was smaller than $20 \mathrm{~mm}$ and about $20 \%$ of it was removed from the circuit during the irrigation stage. Eventually, about 18 tons of feed was introduced into the heavy duty cyclone by the DMS (Dense Medium Separation) process (GSZ's feed method). Based on the results (Table 1), after the separation of materials in the cyclone, a concentrate with a weight of approximately 6 tons was obtained which consists $10 \%$ of the total feed and $20 \%$ of the feed to the cyclone. 
Table 1 The result of heavy media method for the particles with the size smaller than $20 \mathrm{~mm}$

\begin{tabular}{lcccc}
\hline Sample & Weight $(\%)$ & Ash $(\%)$ & Coal $(\%)$ & Recovery $(\%)$ \\
\hline Feed & 100 & 53.80 & - & - \\
Feed with particle size $>20 \mathrm{~mm}$ & 50 & 53.60 & & - \\
Feed with particle size $(0.5-20) \mathrm{mm}$ & & & 84.70 & 8.79 \\
Concentrate & 10 & & 26.80 & 5.94 \\
Tail & 20 & 60.70 & 45.80 & 0.53 \\
Feed with particle size $<0.5 \mathrm{~mm}$ & 20 & & \\
\hline
\end{tabular}

\subsection{The heavy media cyclone at industrial scale}

The results of sink and float experiments are used to select the specific weight of fluid in the hydro-cyclone apparatus. In this research, based on the results of heavy media tests performed at industrial scale, the specific weight of the hydro-cyclone medium was selected and the gravity separation tests of coal tailings has been done in specific weights of $1.40,1.47$ and $1.55 \mathrm{~g} / \mathrm{cm}^{3}$ at industrial scale.

At the entrance of the heavy media cyclone devices, there is a sieve that assumes particles that are smaller than the crater as tailings. Based on the analysis of the gradient carried out on the concentrate and tailings of each of the heavy media cyclones (Fig. 8), it was observed that more than $70 \%$ of the particles are larger than $2 \mathrm{~mm}$, so it can be said that the size of the span which is embedded at the entrance of the heavy media cyclones is $2 \mathrm{~mm}$. Therefore, heavy media cyclone experiments were performed on particles $2-15 \mathrm{~mm}$ in size. The results of these experiments are given in Table 2 for specific weights of $1.40,1.47$ and $1.55 \mathrm{~g} / \mathrm{cm}^{3}$.

\subsection{Heavy liquid tests on a laboratory scale}

As noted above, the evaluation of the separation method or the performance of a gravity separation device is usually

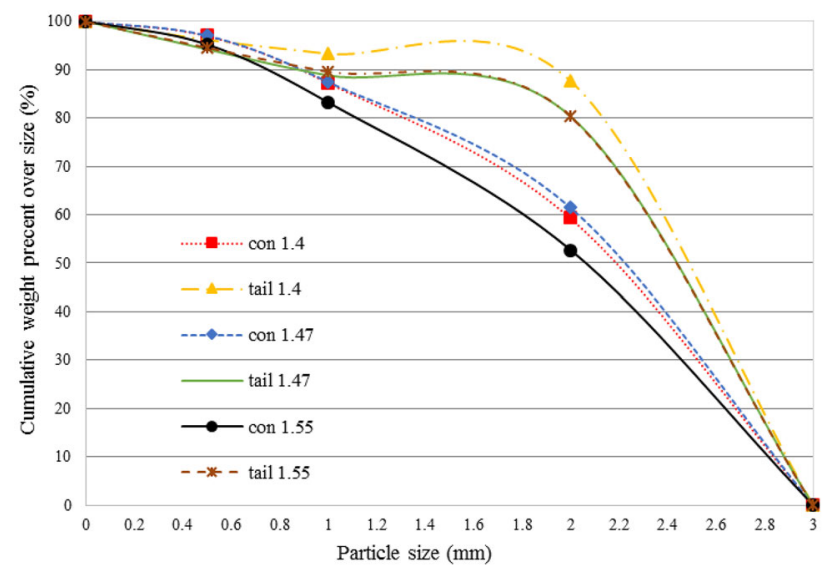

Fig. 8 Analysis of condensate sediment and hydro cyclone tailings on laboratory scale
Table 2 The results of heavy media cyclone at industrial scale

\begin{tabular}{llrl}
\hline Test & Weight $(\mathrm{kg})$ & & $\frac{\text { Weight concentrate }}{\text { weight feed }} \%$ \\
\hline $\begin{array}{c}\text { Density } \\
\left.\mathrm{cm}^{3}\right)\end{array}$ & & 1950 & 5.64 \\
& Concentrate & 110 & \\
& Tail & 510 & \\
Density $1.47 \pm 0.2(\mathrm{~g} /$ & Feed & 1750 & 13.71 \\
$\left.\mathrm{~cm}^{3}\right)$ & Concentrate & 240 & \\
& Tail & 450 & \\
Density $1.55 \pm 0.2(\mathrm{~g} /$ & Feed & 1700 & 17.64 \\
$\left.\mathrm{~cm}^{3}\right)$ & Concentrate & 300 & \\
& Tail & 300 & \\
\hline
\end{tabular}

based on the decomposition of the sinking and floating and the washing ability curves. For this purpose, for assessing the efficiency of heavy media cyclones in different specific weights, sink and float experiments were carried out on concentrates and tailings of hydro-cyclone on a laboratory scale. Heavy liquid solutions required are obtained from dissolving zinc chloride in water. Based on the similar experience obtained from the processing factories, $E_{\mathrm{p}}$ 's probability error rate for this plant was considered 0.05 and the weight of especially heavy liquids were calculated using Eq. (1):

$D_{x}=n \times E_{p} \quad n=1,2, \ldots$

Due to limitations in the preparation of heavy media solutions as well as their cost, the value of $n$ was considered to be 2 and liquids with specific weight of 1.3, 1.5, 1.7, $1.9 \mathrm{~g} / \mathrm{cm}^{3}$. The results of sink and float experiments for the feed of heavy media cyclones in two particle fractions larger than $2 \mathrm{~mm}$ and 1-2 mm are shown in Fig. 9. Also in Fig. 10, the results of analyzing the amount of ash in the feed with the size greater than $1 \mathrm{~mm}$ at each specific gravity are presented.

In Fig. 11, the results of the heavy liquid tests are shown for concentrate and tailing of heavy media cyclone devices with the size of larger than $2 \mathrm{~mm}$. The amount of floated concentrate of the cyclone with a specific weight of $1.40 \mathrm{~g} /$ 

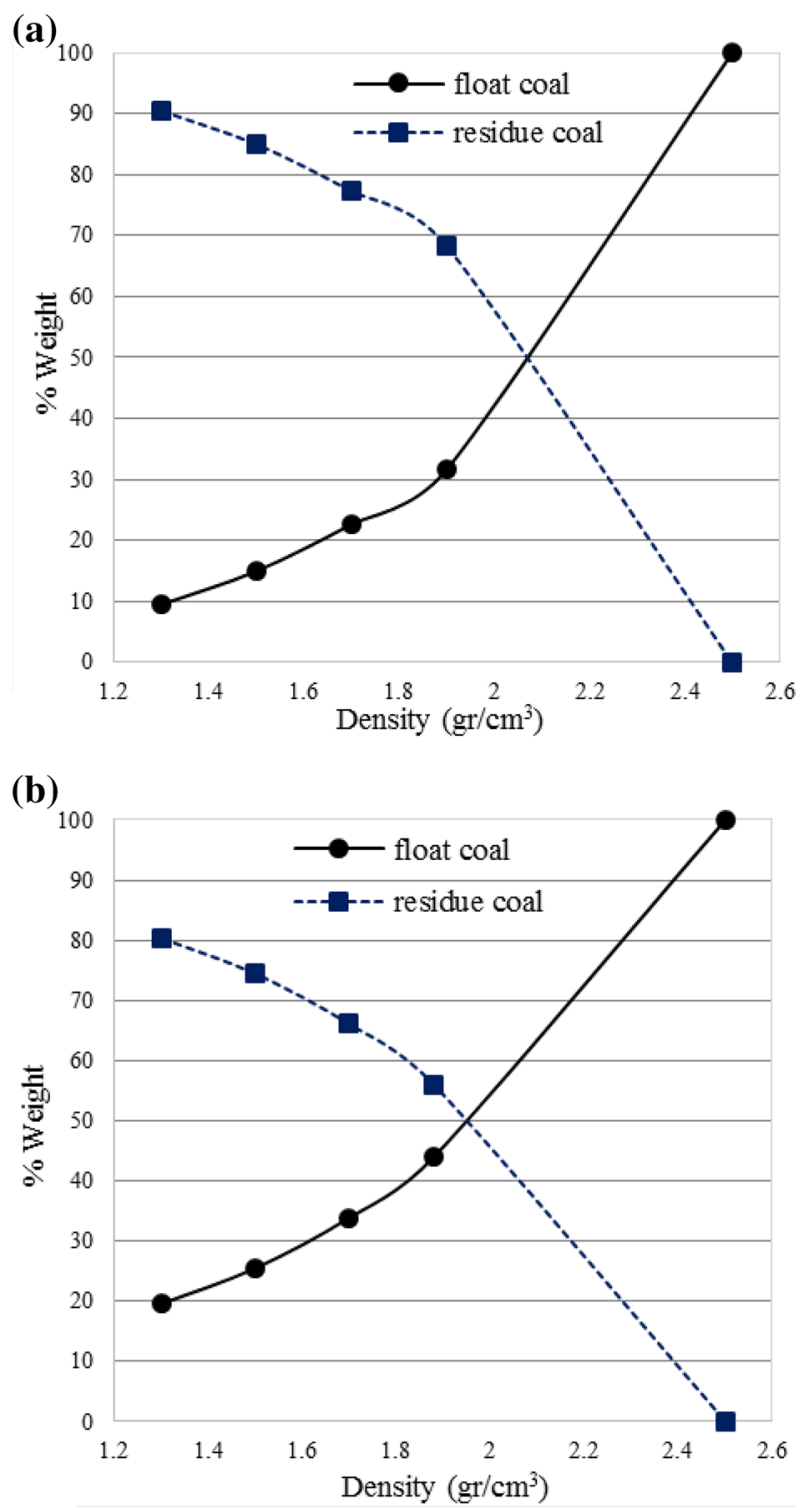

Fig. 9 Results of sink and float experiments for the feed of heavy media cyclones. a Particles larger than $2 \mathrm{~mm}$ in size. b Particles with a size of (1-2) $\mathrm{mm}$

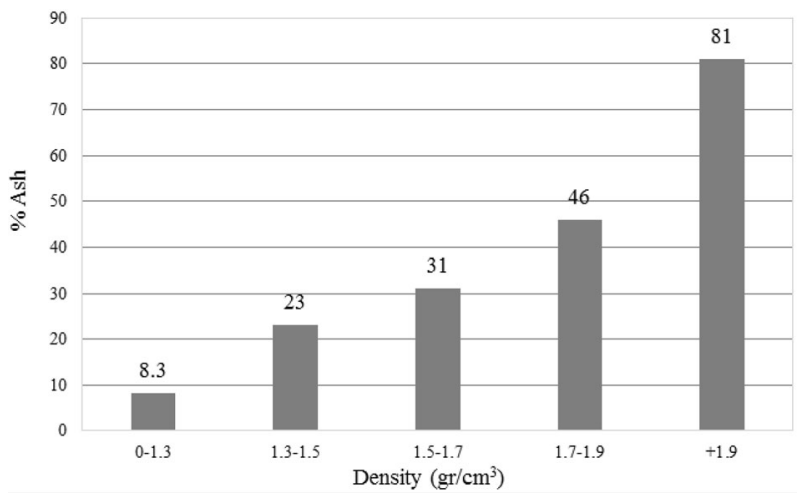

Fig. 10 Analytical results on the amount of ash of hydro cyclone feed in different weights

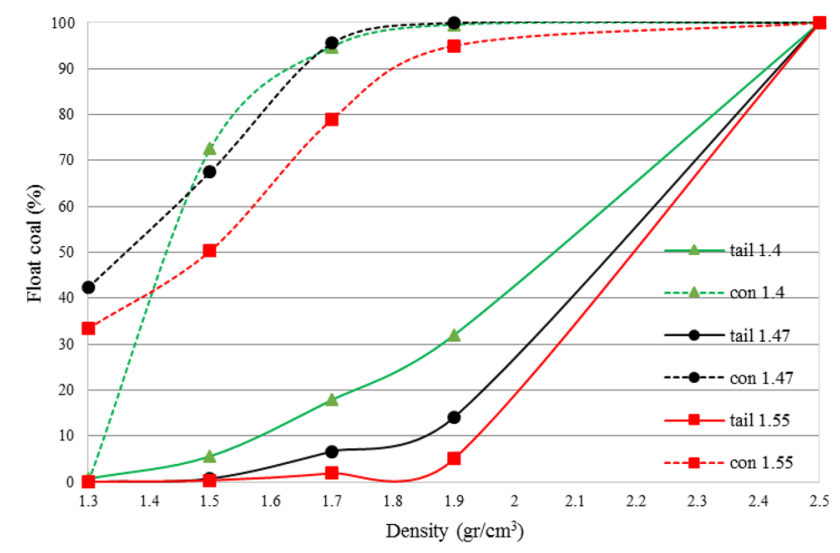

Fig. 11 The results of sink and floating experiments on the concentrate and tailing in heavy media cyclone in laboratory scale. Particles are larger than $2 \mathrm{~mm}$ in size

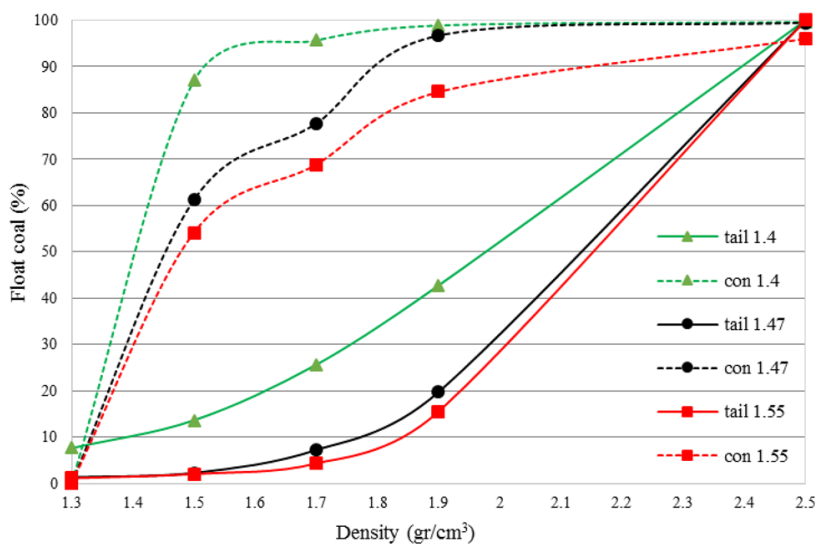

Fig. 12 Experimental results of sink and float experiments for concentrate and tailing of heavy media cyclone. Particles with a size of $1-2 \mathrm{~mm}$

$\mathrm{cm}^{3}$ in a solution of $1.4 \mathrm{~g} / \mathrm{cm}^{3}$ is about $80 \%$ of the feed weight. The proportion of floated coal in the cyclone with the specific weight of $1.47 \mathrm{~g} / \mathrm{cm}^{3}$ in a solution of $1.5 \mathrm{~g} / \mathrm{cm}^{3}$ is $68 \%$, this amount for a cyclone with a specific weight of $1.55 \mathrm{~g} / \mathrm{cm}^{3}$ is $50 \%$.

In order to carry out more precise studies, sink and floating experiments were also performed on size fraction of 1-2 mm concentrates and tailings of cyclones. Figures 12 and 13 show the results of these experiments. The heavy liquid test does not have a good result for particles of less than $2 \mathrm{~mm}$ in size. Therefore, the experiment was not conducted on this fraction.

According to the results of the sink and floating experiments and analyzing the amount of ash, the amount of floated concentrate of the cyclone with a specific weight of $1.40 \mathrm{~g} / \mathrm{cm}^{3}$ in a solution of $1.4 \mathrm{~g} / \mathrm{cm}^{3}$ is over $95 \%$ of the feed weight and the ash contents less than $12 \%$. The specific gravity of the cyclone floated coal is $1.47 \mathrm{~g} / \mathrm{cm}^{3}$ in 


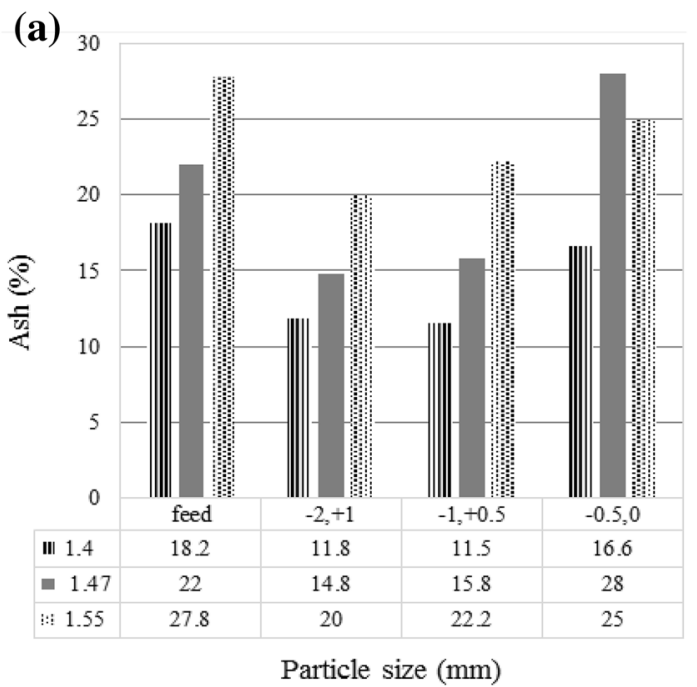

(b)

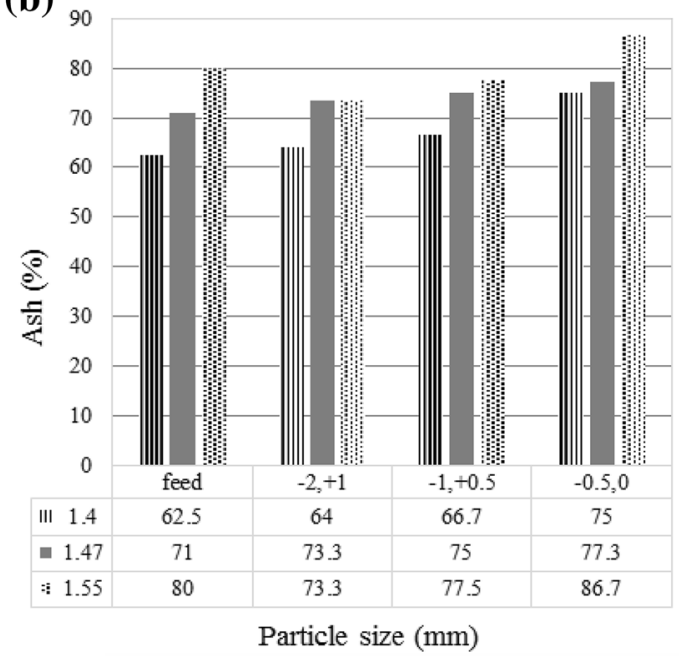

Fig. 13 Test results of laboratory scale measurements for heavy media cyclones. a Concentrate, $\mathbf{b}$ tailings

a solution of $1.5 \mathrm{~g} / \mathrm{cm}^{3}$ is about $78 \%$ with $15 \%$, and this value for the cyclone with a specific weight of $1.55 \mathrm{~g} / \mathrm{cm}^{3}$ is $68 \%$ with $20 \%$ of ash.

\subsection{Plotting the Tromp distribution curve}

The performance of gravity separation equipment's is evaluated by distribution curves. Determining the distribution curves for controlling gravity separation processes is important and can provide a proper correction for controlling a given process, and it is possible to simulate and predict the results (Ferrara and Bevilacqua 1995). The distribution curve is obtained by calculating the distribution coefficient by the average density in each fraction. In order to plot the distribution curve, weighting the concentration of concentrate and sink-float tests for concentrate and tailings should be performed. The weight recovery of the concentrate can be obtained through direct weighting or using mass balance equations. With regard to weight recovery, as well as sink and floating data, the feed can be restored. The data from sink and floating experiments for cyclones with specific weights of media 1.40 , 1.47 and $1.55 \mathrm{~g} / \mathrm{cm}^{3}$ are presented in Tables 3,4 and 5 for plotting the distribution curve.

To plot the Tromp curve, the mass fraction between the floated and sunk coal is required by the separator, these values are calculated by using Eqs. (2) and (3):

Efficiency of floated materials $=\frac{\text { mass of floated materials }}{\text { Mass of total feed }}$

Efficiency of sink materials $=\frac{\text { mass of drowned materials }}{\text { Mass of total feed }}$

According to the data obtained from the sink and floating experiments on the concentrate and tailings of the heavy medium cyclone of Anjir Tange and Eqs. (2) and (3), at a specific weight of $1.40 \mathrm{~g} / \mathrm{cm}^{3}$, the efficiency of floated materials is $17.75 \%$ and efficiency of submerged material is $82.25 \%$. Also, using the specific weight of $1.47 \mathrm{~g} / \mathrm{cm}^{3}$, these values are $33.80 \%$ and $66.20 \%$, respectively. The efficiency of floated materials in cyclones with a specific weight of medium $1.55 \mathrm{~g} / \mathrm{cm}^{3}$ was also 50 percent, and the efficiency of submerged materials was also calculated to be 50 percent. Then, the separation curves or Tromp curves were plotted with a distribution coefficient relative to the mean density range for the three specified weights (Fig. 14).

From the Tromp curve many common performance parameters can be estimated. These parameters include (1) cut point $\left(\rho_{50}\right)$, which is the relative density at which particles report equally to both products; (2) probable error $\left(E_{\mathrm{p}, s}\right)$, which is half of the specific gravity interval between $25 \%$ and $75 \%$ partition values; and (3) imperfection, which relates to the shape of the partition curve (Mohanta and Mishra 2009).

According to the obtained Tromp curves (Fig. 14), $\mathrm{d}_{50}$ at the density of $1.40 \mathrm{~g} / \mathrm{cm}^{3}$ is equal to $1.40 \mathrm{~g} / \mathrm{cm}^{3}$, and at 1.47 and $1.55 \mathrm{~g} / \mathrm{cm}^{3}$, this value is 1.67 and $1.86 \mathrm{~g} / \mathrm{cm}^{3}$, respectively. The actual separation curve shows that the efficiency of the particles with their density at the separation density is the highest, and the efficiency is reduced for particles whose density is close to the separation density (the separation limit). Therefore, given the equalization of the separation density $\left(\mathrm{d}_{50}\right)$ at a specific weight of $1.40 \mathrm{~g} /$ $\mathrm{cm}^{3}$, it can be claimed that the performance of the machine was more appropriate at this particular specific weight. 
Table 3 Analysis of sink and floating tests on the concentrate and tailings of heavy medium cyclone with specific weight of $1.4\left(\mathrm{~g} / \mathrm{cm}^{3}\right)$

\begin{tabular}{|c|c|c|c|c|c|c|c|}
\hline $\begin{array}{l}\text { Separation } \\
\text { density }\left(\mathrm{g} / \mathrm{cm}^{3}\right)\end{array}$ & $\begin{array}{l}\text { Float } \\
\text { product }(\%)\end{array}$ & $\begin{array}{l}\text { Residue } \\
\text { product (\%) }\end{array}$ & $\begin{array}{l}\text { Residue load to } \\
\text { initial load (\%) }\end{array}$ & $\begin{array}{l}\text { Float load to initial } \\
\text { load }(\%)\end{array}$ & $\begin{array}{l}\text { Load } \\
\text { rebuilt (\%) }\end{array}$ & $\begin{array}{l}\text { Density } \\
\left(\mathrm{g} / \mathrm{cm}^{3}\right)\end{array}$ & $\begin{array}{l}\text { Administer } \\
\text { coefficient }(\%)\end{array}$ \\
\hline$(-1.3)$ & 72.55 & 0.70 & 0.58 & 12.88 & 13.45 & - & 4.28 \\
\hline$(1.3-1.5)$ & 22.20 & 4.90 & 04.03 & 3.94 & 7.97 & 1.4 & 50.56 \\
\hline$(1.5-1.7)$ & 4.79 & 12.30 & 10.12 & 0.85 & 10.97 & 1.6 & 92.25 \\
\hline$(1.7-1.9)$ & 0.46 & 14.10 & 11.60 & 0.08 & 11.68 & 1.8 & 99.30 \\
\hline$(+1.9)$ & 0.00 & 68.00 & 55.93 & 0.00 & 55.93 & - & 100 \\
\hline Total & 100 & 100 & 82.25 & 17.75 & 100 & - & - \\
\hline
\end{tabular}

Table 4 Analysis of sink and float test on the concentrate and tailings of heavy medium cyclone with specific weight of $1.47\left(\mathrm{~g} / \mathrm{cm}^{3}\right)$

\begin{tabular}{|c|c|c|c|c|c|c|c|}
\hline $\begin{array}{l}\text { Separation } \\
\text { density }\left(\mathrm{g} / \mathrm{cm}^{3}\right)\end{array}$ & $\begin{array}{l}\text { Float } \\
\text { product }(\%)\end{array}$ & $\begin{array}{l}\text { Residue } \\
\text { product }(\%)\end{array}$ & $\begin{array}{l}\text { Residue load to } \\
\text { initial load (\%) }\end{array}$ & $\begin{array}{l}\text { Float load to initial } \\
\text { load }(\%)\end{array}$ & $\begin{array}{l}\text { Load } \\
\text { rebuilt (\%) }\end{array}$ & $\begin{array}{l}\text { Density } \\
\left(\mathrm{g} / \mathrm{cm}^{3}\right)\end{array}$ & $\begin{array}{l}\text { Administer } \\
\text { coefficient }(\%)\end{array}$ \\
\hline$(-1.3)$ & 42.34 & 0.06 & 0.04 & 14.35 & 14.38 & - & 0.28 \\
\hline$(1.3-1.5)$ & 25.11 & 0.67 & 0.44 & 8.49 & 8.93 & 1.4 & 4.97 \\
\hline$(1.5-1.7)$ & 28.73 & 6.68 & 4.42 & 9.46 & 13.88 & 1.6 & 31.85 \\
\hline$(1.7-1.9)$ & 4.42 & 14.09 & 9.34 & 1.49 & 10.83 & 1.8 & 86.20 \\
\hline$(+1.9)$ & 0.30 & 78.50 & 51.96 & 0.01 & 51.98 & - & 99.97 \\
\hline Total & 100 & 100 & 66.20 & 33.8 & 100 & - & - \\
\hline
\end{tabular}

Table 5 Analysis of sink and float test on the concentrate and tailings of heavy medium cyclone with specific weight of $1.55\left(\mathrm{~g} / \mathrm{cm}^{3}\right)$

\begin{tabular}{llllclcl}
\hline $\begin{array}{l}\text { Separation } \\
\text { density }\left(\mathrm{g} / \mathrm{cm}^{3}\right)\end{array}$ & $\begin{array}{l}\text { Float } \\
\text { product }(\%)\end{array}$ & $\begin{array}{l}\text { Residue } \\
\text { product }(\%)\end{array}$ & $\begin{array}{l}\text { Residue load to } \\
\text { initial load }(\%)\end{array}$ & $\begin{array}{l}\text { Float load to initial } \\
\text { load }(\%)\end{array}$ & $\begin{array}{l}\text { Load } \\
\text { rebuilt }(\%)\end{array}$ & $\begin{array}{l}\text { Density } \\
\left(\mathrm{g} / \mathrm{cm}^{3}\right)\end{array}$ & $\begin{array}{l}\text { Administer } \\
\text { coefficient }(\%)\end{array}$ \\
\hline$(-1.3)$ & 33.50 & 0.07 & 0.035 & 16.75 & 16.78 & - & 0.21 \\
$(1.3-1.5)$ & 16.90 & 0.28 & 0.14 & 8.45 & 8.59 & 1.4 & 1.63 \\
$(1.5-1.7)$ & 28.60 & 1.56 & 0.78 & 14.30 & 15.08 & 1.6 & 5.17 \\
$(1.7-1.9)$ & 16.00 & 3.12 & 1.56 & 2.00 & 9.56 & 1.8 & 16.32 \\
$(+1.9)$ & 5.00 & 94.97 & 47.48 & 50 & 49.98 & - & 94.99 \\
Total & 100 & 100 & 50 & & & 100 & - \\
\hline
\end{tabular}

\subsection{Curve slope and coefficient of variation}

Generally, the distribution curves are linear at the distribution coefficients of $25 \%$ and $75 \%$, the slope of this part of the curve is a criterion for separation, and is expressed in Eq. (4):

$E_{\mathrm{p}}=\frac{(\rho(25)-\rho(75))}{2}$

The probability error is the characteristic of a process and separators with less $E_{\mathrm{p}}$ are evaluated as effective separators. The variation of $E_{\mathrm{p}}$ 's dispersion criterion to centralized variation is also a violation factor. The violation coefficient, independent of the separation density, is used as an auxiliary method for comparing separation processes and is defined as the Eq. (5):

$I=\frac{E_{\mathrm{p}}}{\mathrm{d}_{50}-1}$

As noted above, the slope of the curve is a parameter to measure the degree of separation and indicate the separation accuracy. The slope of the distribution curve of Fig. 14 is approximately linear in the distance between the distribution coefficients of $25 \%$ and $75 \%$, so this slope can be used to represent the efficiency. Also, the slope in the density of $1.40 \mathrm{~g} / \mathrm{cm}^{3}$ relative to other densities indicates a better performance of the device in this particular weight. The linear distribution of the distribution curve (the distance between the distribution coefficients of $25 \%$ and 


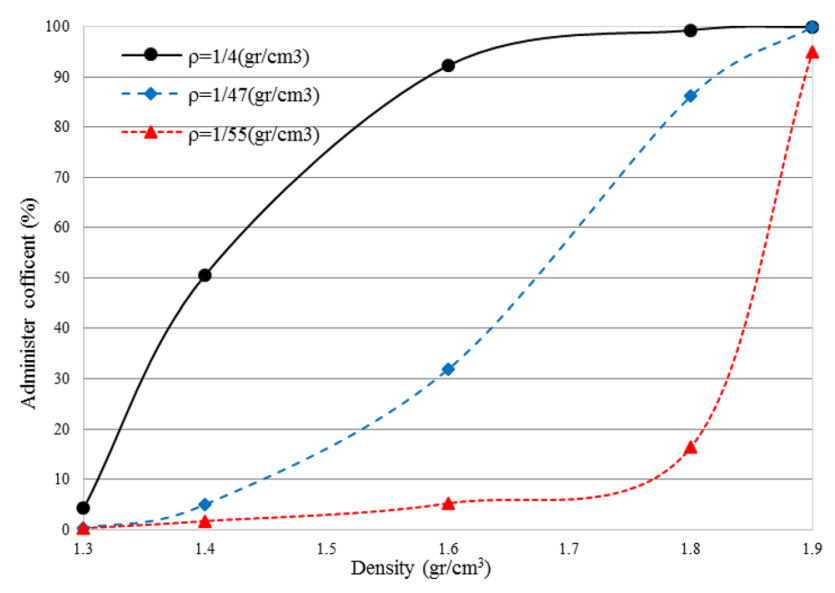

Fig. 14 Distribution curve for cyclones with specific weights of 1.40, 1.47 and $1.55 \mathrm{~g} / \mathrm{cm}^{3}$

$75 \%)$ is closer to the straight line, the $\mathrm{E}_{\mathrm{p}}$ value is smaller and the separation efficiency is greater. In an ideal separation, this line is straight and the $E_{\mathrm{p}}$ value is zero. In this study, the calculated value of $E_{\mathrm{p}}$ for a heavy media cyclone with a density of $1.40 \mathrm{~g} / \mathrm{cm}^{3}$ equals to 0.080 and at the specific weight of 1.47 , this value is 0.085 . Also, this value is 0.030 for a specific weight of $1.55 \mathrm{~g} / \mathrm{cm}^{3}$. According to the Eq. (5), the coefficient of variations are also calculated for the Tromp curve at the specific weights of 1.40, 1.47 and $1.55 \mathrm{~g} / \mathrm{cm}^{3}$ as $0.20,0.12$ and 0.03 , respectively.

\section{Conclusion}

Based on the results of industrial scale experiments, by performing heavy medium tests, products with various qualities are obtained. In the size fraction larger than $1 \mathrm{~mm}$, the recovery will be $19 \%$ for the product with $7 \%$ ash, the product with $12 \%$ of the feed weight will have $30 \%$ recovery, and the recovery of the product with $22.50 \%$ ash is $45 \%$. In the case of combining products with the size of larger than $1 \mathrm{~mm}$ and spiral products (particles smaller than $1 \mathrm{~mm}$ ), concentrate with $18 \%$ ash and $48.50 \%$ recovery is produced, which is $22.50 \%$ of the feed weight. According to these experiments, specific weights of media $1.40,1.47$ and $1.55 \mathrm{~g} / \mathrm{cm}^{3}$ was considered appropriate for cyclones. The performance of hydro cyclones was investigated by conducting sink and floating experiments. According to the obtained data, in specific weights of media $1.40,1.47$ and $1.55 \mathrm{~g} / \mathrm{cm}^{3}$, the efficiency of floated materials were $17.75,33.80$ and 50 percent, and the values of sunk materials were above $82.25,66.20$ and $50 \%$. According to the curvatures of the tromp $\mathrm{d}_{50}$, the separation curve in the density of $1.40 \mathrm{~g} / \mathrm{cm}^{3}$ is $1.00 \mathrm{~g} / \mathrm{cm}^{3}$ and in the density of 1.47 and $1.55 \mathrm{~g} / \mathrm{cm}^{3}$, this value is 1.67 and $1.86 \mathrm{~g} / \mathrm{cm}^{3}$. According to the equalization of the separation density $\left(\mathrm{d}_{50}\right)$ at a specific weight of $1.40 \mathrm{~g} / \mathrm{cm}^{3}$, it can be claimed that the function of the machine is suitable for this specific weight. The calculated probability error value for a heavy medium cyclone with a density of $1.40 \mathrm{~g} / \mathrm{cm}^{3}$ is 0.080 and at the specific weight of 1.47 , this error is 0.085 . Also, this value is 0.030 for a specific weight of $1.55 \mathrm{~g} /$ $\mathrm{cm}^{3}$. The value of the imperfection coefficient for the tromp curve of Anjir Tange coal preparation plant at specific weights of $1.40,1.47$ and $1.55 \mathrm{~g} / \mathrm{cm}^{3}$ are $0.20,0.12$ and 0.03 , respectively.

Open Access This article is distributed under the terms of the Creative Commons Attribution 4.0 International License (http://crea tivecommons.org/licenses/by/4.0/), which permits unrestricted use, distribution, and reproduction in any medium, provided you give appropriate credit to the original author(s) and the source, provide a link to the Creative Commons license, and indicate if changes were made.

\section{References}

Adiansyah JS, Haque N, Rosano M, Biswas W (2017) Application of a life cycle assessment to compare environmental performance in coal mine tailings management. J Environ Manag 199:181-191

Ashghari M, Noaparast M, Shafaie SZ, Ghassa S, Chehreh Chelgani S (2018) Recovery of coal particles from a tailing dam for environmental protection and economical beneficiations. Int $\mathrm{J}$ Coal Sci Technol 5(2):1-11

Battioui M (2013) Impact of mining wastes on groundwater quality in the province Jerada. Int J Eng Sci Technol 8:1601-1615

BP Statistical Review of World Energy (2017) 66th edition. https:// www.bp.com/content/dam/bp/en/corporate/pdf/energy-econom ics/statistical-review-2017/bp-statistical-review-of-worldenergy-2017-full-report.pdf. Accessed June 2017

Burt R (1984) Gravity concentration technology, developments in mineral processing. Elsevier Science Publishers, Amsterdam

Chu KW, Wang BA, Yu A (2009) CFDDEM modeling of multiphase flow in dense medium cyclones. Int $J$ Miner Process 193:235-247

Chu KW, Wang B, Yu AB, Vince A (2012) Particle scale modelling of the multiphase flow in a dense medium cyclone: effect of vortex finder outlet pressure. Miner Eng 31:46-58

Delgadillo JA, Rajamani RK (2005) Hydro cyclone modeling: large eddy simulation CFD approach. Miner Metall Process 22:225-232

Farzanegan A, Gholami M, Rahimyan MH (2013) Multiphase flow and tromp curve simulation of dense medium cyclones using computational fluid dynamics. J Min Environ 4(1):67-76

Ferrara G, Bevilacqua P (1995) Relationship between apparent and actual partition curves of gravity separation processes. In: Proceedings of the XIX IMPC, SME, New York, American, 2:131-138

Gupta A, Yan DS (2006) Mineral processing design and operation. Elsevier, New York

John G, Rayner JG, Napier-Munn TJ (2002) A mathematical model of recovery of dense medium magnetic in the wet drum magnetic separator. Int J Miner Process 69:157-173

Kefeni KK, Msagati T, Mamba BB (2017) Acid mine drainage: prevention, treatment options, and resource recovery: a review. J Clean Prod 151:475-493 
Kotsiopoulos A, Harrison STL (2017) Application of fine desulfurised coal tailings as neutralising barriers in the prevention of acid rock drainage. Hydrometallurgy 168:159-166

Majumder A, Barnwal J (2011) Processing of coal fines in a wateronly cyclone. Fuel 90(2):834-837

Meck M, Love D, Mapani B (2006) Zimbabwean mine dumps and their impacts on river water quality - a reconnaissance study. Phys Chem Earth 31:797-803

Mohanta S, Mishra BK (2009) On the adequacy of distribution curves used in coal cleaning-a statistical analysis. Fuel 88:2262-2268

Napier T, Barry A, Wills BA (2006) Mineral processing technology, 7th edn. Elsevier Ltd, New York, pp 248-249

Peiravi M, Mote SR, Mohanty MK, Liu J (2017) Bioelectrochemical treatment of acid mine drainage (AMD) from an abandoned coal mine under aerobic condition. J Hazard Mater 333:329-338
Rayner JG, Napier-Munn TJ (2002) Simulation of dense medium recovery circuite. In: Dense media 2002. BHP Billiton

Sengupta M (1993) Environmental impacts of mining-monitoring, restoration and control. Lewis, London, pp 1-31

Siboni N, Fine M, Bresler V, Loya Y (2004) Coastal coal pollution increases $\mathrm{Cd}$ concentrations in the predatory gastropod Hexaplex trunculus and is detrimental to its health. Mar Pollut Bull 49:111-118

Simate GS, Ndlovu S (2014) Acid mine drainage: challenges and opportunities. J Environ Chem Eng 2:1785-1803

Wills BA (2011) Wills' mineral processing technology: an introduction to the practical aspects of ore treatment and mineral recovery. Butterworth-Heinemann, Oxford 